\title{
PAF Physiology in Target Organ Systems-A Deep Dive to Understand the PAF Mystery in Pathogenesis of Disease
}

\author{
Nilank Shah *, Karan Kumar and Nikeith Shah \\ Touro College of Osteopathic Medicine, 60 Prospect Ave, Middletown, NY 10940, USA; \\ Kkumar3@student.touro.edu (K.K.); nshah2@student.touro.edu (N.S.) \\ * Correspondence: nilank.shah@touro.edu
}

check for updates

Citation: Shah, N.; Kumar, K.; Shah, N. PAF Physiology in Target Organ Systems-A Deep Dive to Understand the PAF Mystery in Pathogenesis of Disease. Hearts 2021, 2, 551-560. https://doi.org/10.3390/ hearts2040042

Academic Editor: Federico Biscetti

Received: 28 October 2021

Accepted: 25 November 2021

Published: 29 November 2021

Publisher's Note: MDPI stays neutral with regard to jurisdictional claims in published maps and institutional affiliations.

Copyright: (c) 2021 by the authors. Licensee MDPI, Basel, Switzerland. This article is an open access article distributed under the terms and conditions of the Creative Commons Attribution (CC BY) license (https:/ / creativecommons.org/licenses/by/ $4.0 /)$.

\begin{abstract}
The purpose of this literature review is to gain an overview of the role of platelet-activating factor (PAF) within each of the body systems and how it contributes to normal and pathophysiological states. The review showed that there are multiple functions of PAF that are common to several body systems; however, there is little evidence to explain why PAF has this affect across multiple systems. Interestingly, there seems to be conflicting research as to whether PAF is an overall protective or pathogenic pathway. Within this research, it was found that there are different pathways depending on the specific body system, as well as between body systems. However, one universal function reported in the literature is of PAF as a pro-inflammatory molecule. Overall, this review identified five major functions of PAF: vasoconstriction, increased inflammation, vascular remodeling, increased edema, and endothelial permeability.
\end{abstract}

Keywords: platelet-activating factor; inflammation; atherosclerosis; platelet-activating factor acetyl hydrolase

\section{Introduction}

Platelet-activating factor (PAF) is a phospholipid mediator and activator that plays a role in many physiologic and pathologic states. It is secreted by a variety of circulatory cells in the human body, including immune system cells, endothelium, smooth muscle, platelets and cardiomyocytes [1]. It is also produced by cells of many organ systems, including the brain, eyes, heart, lungs and gastrointestinal tract. There are two predominant cellular pathways in which PAF is produced, the remodeling pathway and the de novo pathway. The remodeling pathway, which is considered the primary pathway in which PAF is produced, consists of modifying the structure of existing membrane phospholipids via phospholipase A2 (PLA-2) [1]. The de novo pathway, which has been observed in the brain and kidney, consists of adding phosphocholine to a 1-0-alkyl-2-acetyl-sn-glycerol molecule (Figure 1) [1-3].

When PAF is released, it binds to the PAF receptor (PAFR), a G-protein-coupled receptor. This leads to regulation of cytoplasmic calcium concentrations, phosphatidylinositol turnover, increased cAMP levels and phosphorylation of proteins. The downstream effects lead to increased leukocyte adhesion, chemotaxis, leukocyte degranulation, endothelial permeability, vasodilation and vasoconstriction [1]. Additionally, it has been observed that PAF leads to increased proinflammatory markers such as interleukin 1 beta (IL-1 $\beta$ ), interleukin 6 (IL-6), interleukin 8 (IL-8) and tumor necrosis factor alpha (TNFa) [4]. Even at concentrations as low as $10^{14} \mathrm{~mol} / \mathrm{L}, \mathrm{PAF}$ has been shown to be able to activate these proinflammatory markers.

PAF acts upon platelets to aggregate and release thromboxane A2 and beta thromboglobulin [1]. Downstream from this, there is an increase in eicosanoids and TNF-a which leads to additional PAF release and increased platelet activation. This leads to a net increase in PAF-induced platelet reactivity. Overall, the most reported effect for PAF has been an 
increase in inflammatory pathways [1]. While such acute inflammation is necessary for wound healing, prolonged inflammation leads to poor wound healing.

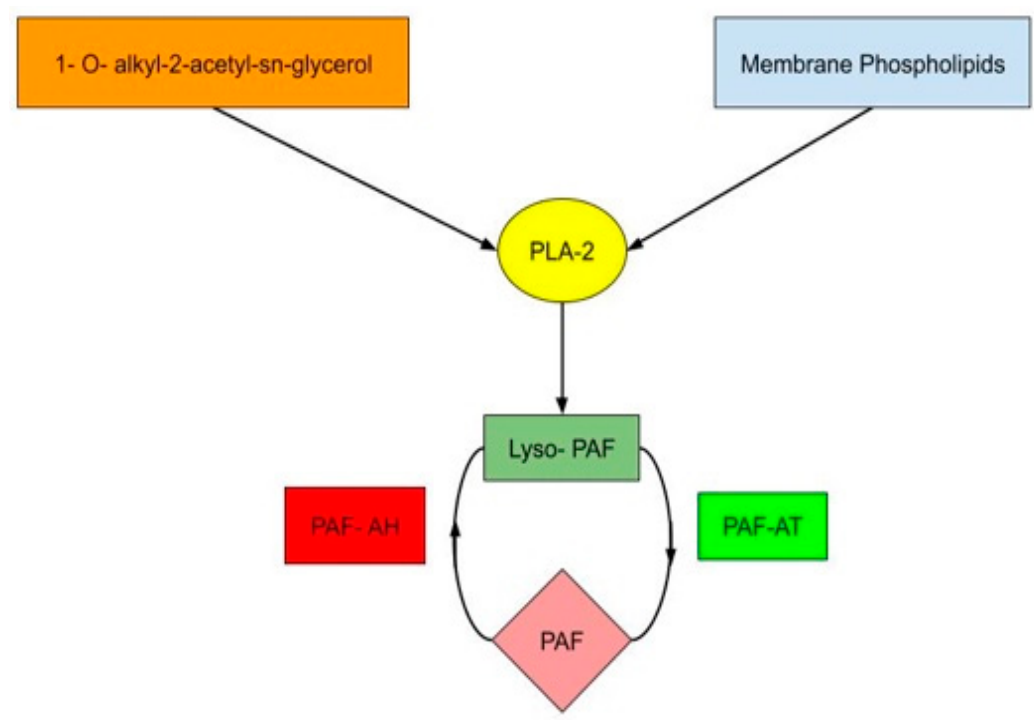

Figure 1. PAF production via the remodeling and de novo pathway. Phospholipase A2 (PLA-2) is a central point of PAF production via the modification of existing membrane phospholipids and the addition of phosphocholine to 1-0-alkyl-2-acetyl-sn-glycerol. Platelet-activating factor acyltransferase (PAF-AT) takes this further to form functional PAF, whereas platelet-activating factor acytelhydrolase (PAF-AH) breaks down PAF into its inactive form.

Levels of PAF are primarily controlled via two enzymes, PAF acetyltransferase and PAF acetylhydrolase (PAF-AH) [1]. PAF acetyltransferase converts lysophosphatidylcholine (Lyso-PAF) into the active PAF, while PAF acetylhydrolase converts PAF into the inactive Lyso-PAF. These two enzymes create a physiological balance of PAF activity in organ systems. Unchecked regulation of PAF plays a major role in the pathophysiology of numerous inflammatory reactions and leads to diseases discussed here. Each organ system that PAF is involved in represents an avenue for medical breakthrough in understanding the pathophysiology of chronic diseases, including asthma, diabetes, atherosclerosis and renal diseases [5]. PAF has also been implicated in acute disease processes, such as acute coronary syndrome, necrotizing enterocolitis (NEC), acute respiratory distress syndrome (ARDS) and bacterial infections. This review aims to provide a review of PAF's functions within some of the primary organ systems, including the brain, spinal cord, eye, and cardiovascular, respiratory, and gastrointestinal systems.

\section{Brain and Spinal Cord}

Within the central nervous system, PAF is known to be involved with the signaling pathways in neurons, microglia, astrocytes and oligodendrocyte progenitor cells [6]. These cells contain the universal PAF receptor (PAFR), which allows PAF to signal via Gq and Gi pathways to increase intracellular calcium levels and leukocytic activation/motility, respectively.

A possible link between PAF and its role in the activation of cholesterol esters has been hypothesized to be involved in the progression of Alzheimer's disease. Patients with Alzheimer's disease are known to have an increase in amyloid beta, cholesterol, and prostaglandin $\mathrm{E}_{2}\left(\mathrm{PGE}_{2}\right)$. It has been shown that PAF is involved with the activation of cholesterol ester hydrolases leading to downstream increases in $\mathrm{PGE}_{2}$. A key modulator of PAF is cytosolic phospholipase A2 (cPLA-2). When cPLA-2 is activated, its downstream effects cause an increase in PAF levels. In the presence of cPLA-2 inhibitors and PAF antagonists, there is a decrease in cholesterol esters found within the amyloid beta synapses, providing evidence that a rise in PAF and activation of cPLA-2 is a vital step in activating 
cholesterol ester hydrolases. This relation was found to be key in the connection between PAF, amyloid beta, and cholesterol ester levels, all of which are elevated in Alzheimer's disease. Amyloid-beta-induced increase in PAF levels and subsequent increase in cholesterol esters stabilizes a complex which signals an increase in $\mathrm{PGE}_{2}$ and neuronal synapse degeneration [7].

PAF has also been shown to increase ocular and cerebral levels of matrix metallopeptidases (MMPs) 2 and 9 during cerebral infarctions. During infarct, there are markedly increased levels of PAF, which presents a poor prognosis of disease [8]. After the rise in PAF, cAMP response element binding (CREB) protein is phosphorylated leading to activation of activating transcription factor 1 and subsequent increase in MMP [8]. Following the rise in PAF, there is a decrease in vascular endothelial growth factor (VEGF). This inhibits angiogenesis, neurogenesis, and neuroprotection (Figure 2) [8]. Furthermore, utilizing a human recombinant PAF-AH, at a dose of $1 \mathrm{mg} / \mathrm{kg}$, to break down PAF, it has been shown to remove these negative effects and to restore a protective state following infarct [8]. Additionally, a study on the microvasculature of the brain showed an increase in permeability of the blood brain barrier following an increase in PAF [9]. This was mediated largely through the VEGF pathway, with downstream activation of the PI3k/Akt pathway [9]. Similarly to the eye, increases in PAF also increased cytosolic calcium in the microvasculature of the brain. Specifically the calcium influx was mediated through L-type calcium channels which was successfully shown to be diminished with the use of nifedipine [9]. This calcium influx is thought to be the reason behind the increase in intercellular gaps and decrease in the number of tight junctions within vessels after exposure to PAF [9]. A direct correlation was observed between PAF and decrease in Zona occludens - 1 and increase in F-actin, which led to increased blood brain barrier permeability and increased intercellular gaps, respectively [9].

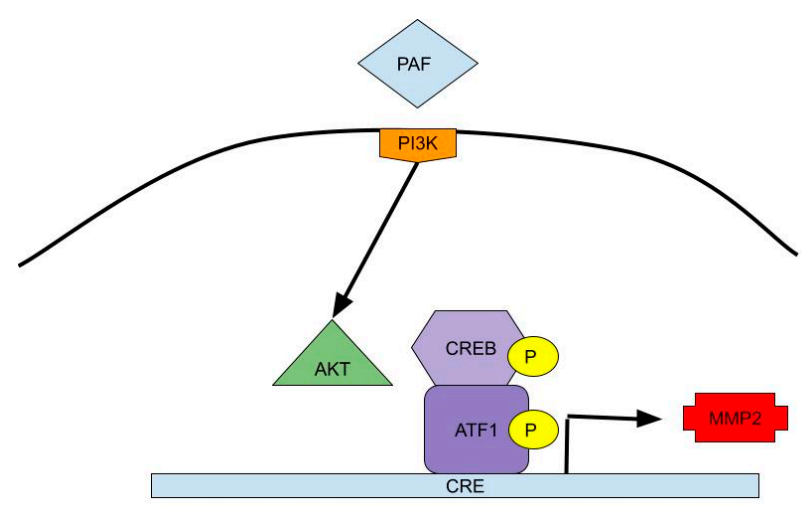

Figure 2. PAF has been linked to an increase in MMP2 and MMP9 via the phosphorylation of CREB and subsequent ATF1 activation.

In the spinal cord, a different phenomenon is observed with PAF levels. Following spinal cord injury, PAF has both beneficial and harmful effects in the late phase of recovery. PAF activates glial scar formation, which is initially immune-protective; however, it creates later complications for axonal regrowth [10]. When PAF is blocked, glial fibrillary acidic protein, vimentin, nestin and proinflammatory cytokine levels are reduced, which suggests a blockage of glial scar formation and increase in axonal regrowth [10]. It has been hypothesized that there is a connection between the mTOR pathway and PAF, as glial scar formation is known to be connected to activation of the mTOR pathway [11].

\section{Eye}

Immediately following corneal injury, the level of PAF rises exponentially and has been noted to be directly proportional to the severity of the injury sustained [12]. As a result of the increase in PAF, the MAPK and CPLA-2 pathways are activated, leading to downstream activation of c-Jun and NF- $\mathrm{KB}$ [13]. As a consequence of MAPK activation, the 
expression of MMP and the tissue inhibitor, metalloproteinase, occurs [13]. Interestingly, PAF increases both the proteinase as well as its inhibitor in an uneven fashion, ultimately resulting in suppression of the wound-healing process by the increase in MMP. PAF is a highly potent activator of the phospholipase C pathway [14]. Activation of this pathway induces a calcium influx, which is thought to induce the expression of COX-2. COX-2 then leads to sustained inflammation during a time of corneal injury. This, coupled with the increased expression of MMP, provides evidence that PAF expression may increase inflammation and wound healing time in the eye.

\section{Heart}

PAF has a wide array of effects on the heart, coronary vessels, and peripheral vasculature. PAF's role in the heart itself is complex, as it has both protective and harmful effects. At low doses, PAF has been shown to have cardioprotective effects. In postischemic studies, for example, administration of low-dose PAF reduced infarct size and left-ventricular-developed pressure $[15,16]$. The mechanism by which this occurs is not clearly understood but adenosine receptors may play a role, as the use of adenosine receptor antagonists was observed to partially blunt the cardioprotective effect of PAF [15].

PAF can also have harmful effects on coronary vascular resistance, in a dose-dependent manner [17]. High doses of PAF increase systemic vascular resistance. PAF also reduces venous blood return due to peripheral vasodilation, thereby decreasing cardiac output [17]. It also increases pulmonary vascular resistance, through the release of histamine and thromboxane A2 from platelets, which can lead to right ventricular overload [17]. These effects of PAF point towards a promising avenue for the development of PAF antagonists to be used in diseases such as myocardial infarction and cor pulmonale.

PAF has been shown to stimulate reactive oxygen species (ROS) and reactive nitrogen species (RNS), both of which can alter the properties of cholesterols and phospholipids, making them atherogenic and immunogenic. Peroxynitrite, an RNS, has been shown to induce vascular endothelial permeability in the presence of PAF as well as to deactivate PAF-AH which leads to worsening atherogenesis [1]. A clinical study of a subset of a Chinese population found that higher levels of PAF contributed to risk of coronary heart disease [18]. Interestingly, research has shown that PAF-AH levels affect progression of atherosclerosis. An increase in TNF-a and interferon (IFN) can decrease PAF-AH secretion from macrophages, leading to protection against atherogenesis [1].

$\mathrm{PAF}$ is a known potentiator of vascular remodeling in hypertension and atherosclerosis in the context of magnesium deficiency. Vascular remodeling involves numerous cellular processes including cell growth, differentiation, migration, and death, all of which are connected to the proto-oncogenes $c-f o s$ and $c-j u n$. It has been shown that PAF is synthesized and released prior to upregulation of the $c-f o s$ and $c-j u n$ proto-oncogenes, generating the hypothesis that upregulation of these proto-oncogenes by PAF may contribute to eventual vascular remodeling changes [19]. Magnesium deficiency, although independently associated with atherosclerosis, due to a direct decrease in prostaglandin $\mathrm{I} 2$ and nitric oxide (NO), has also been found to affect PAF levels [20]. In a condition of magnesium deficiency, PAF levels are seen to be greatly increased, thus evidencing a potential relationship between magnesium and the atherosclerotic effects of PAF [20]. Similarly, PAFR antagonists have been shown to greatly attenuate the PAF-stimulated formation of these proto-oncogenes, showing a relationship between PAF and the upregulation of these proto-oncogenes [21]. Continuous PAF signaling in vascular endothelial cells has also been shown to cause endothelial cell dysfunction by decreasing the bioavailability of nitric oxide, further supporting its role in the vascular system [1].

\section{Lungs}

PAF has a variety of effects in the lungs, including promoting airway hyperreactivity, and inducing vascular permeability, vasoconstriction, bronchoconstriction and edema formation [22]. These effects are mediated by eicosanoids and sphingolipids. PAF-induced 
pressor responses are specifically mediated by thromboxane A2 and leukotrienes, while PAF-induced increases in vascular permeability are mediated by prostaglandin E2 and ceramide. The specific pressor response by thromboxane primarily depends on the enzyme Rho-kinase and other calcium-sensitizing mechanisms [23]. Activation via Rho-kinase leads to MLC phosphorylation and downstream thromboxane mediated pulmonary vascular constriction [23]. PAF has numerous chronic effects as well, including vascular remodeling, lowering pulmonary vascular compliance, goblet cell hyperplasia and increased mucin gene expression by the airway [24].

Patients with cystic fibrosis are at an increased risk of bacterial infections, in part due to the PAFR [20]. Gram-positive bacteria, such as Staphylococcus aureus, contain lipoteichoic acid (LTA) which is a major component of the cell wall. Upon bacterial invasion of human epithelial cells, LTA induces internalization of the PAFR. This leads to EGFR transactivation via ADAM10 proteolysis of HB-EGF and eventual Ras activation for a final product of increased mucin production [20,24,25]. Overproduction of mucus subsequently obstructs airflow leading to increased respiratory effort required for normal oxygenation. Increased mucus production shields less superficial bacteria from antibiotics, leading to unchecked bacterial multiplication and possible development of antibiotic resistance [26].

The bacterium Streptococcus pneumoniae has also been shown to invade host cells through the PAFR [27]. PAFR can bind to phosphorylcholine which is present in the bacterial cell wall, thus facilitating endocytosis and transcytosis [28]. Further compounding this is the fact that pneumococcal infections cause the production of pro-inflammatory cytokines such as IL-1 $\beta$ and TNF-a [28]. These cytokines upregulate the PAFR, thus leading to a positive feedback loop and increased potential for Streptococcus pneumoniae to bind and invade host cells. Cigarette smoke has been shown to increase epithelial PAFR expression which allows bacteria such as Streptococcus pneumoniae and Haemophilus influenzae to colonize their hosts more easily (Figure 3) [29].

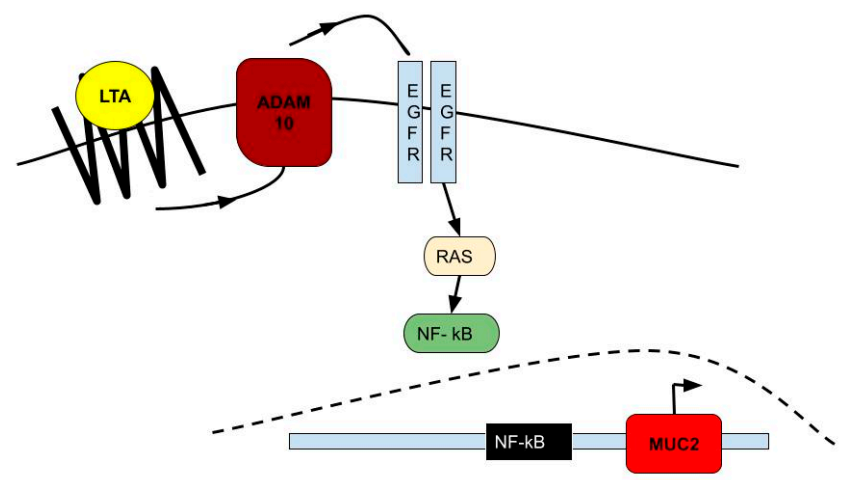

Figure 3. LTA from Gram-positive bacteria induces increased mucus production via the PAFR which activates the ADAM10 pathway leading to mucin 2 (MUC2) transcription via NF- kB.

The development and progression of several respiratory diseases has also been shown to have a relation to PAF. Decreased expression of PAF-AH has been observed in plasma samples of ARDS patients compared to at-risk control patients, suggesting that increased levels of PAF may be involved in the pathogenesis of ARDS [30]. Decreased PAF-AH gene transcription levels may reduce the ability of ARDS patients to limit the extent of lung injury due to the inflammation caused by PAF [30]. The absence or antagonism of PAFR leads to significant protection against influenza A-mediated lung injury and death in mice [31]. Protection was measured by decreased neutrophil recruitment/activation, vascular permeability/injury and lung edema [31]. Cigarette smoke exposure has been shown to promote the progression of diseases such COPD and emphysema due to PAFR. Cigarette smoke induces autophagy in neutrophils, leading to the release of elastase. Elastase damages lung parenchyma, leading to progression of COPD and emphysema [32]. PAF promotes trans-endothelial migration of polymorphonuclear leukocytes in small airways, thus worsening inflammation [33]. 
Components of cigarette smoke not only increase the expression of cell-surface adhesion molecules (to bind PMNs), but they also inhibit PAF-AH in human lung endothelial cells, thus enhancing PAF production and promoting inflammation. Smokers and patients with COPD have been shown to have increased expression of PAFR. This may explain why patients with COPD are more likely to have chronic and invasive infections with Streptococcus pneumoniae and Haemophilus influenzae [34,35].

\section{Gastrointestinal}

Within the gastrointestinal system, PAF shows modulation of the inflammatory system as well as cytosolic calcium levels. Together, these processes lead to the pathogenesis of several disease states. Most notably, PAF has implications in diseases such as necrotizing enterocolitis, reperfusion injury, and even adipose inflammation. While PAF shows specifically proinflammatory effects in many other body systems, it may have a more fluid role within the gastrointestinal system.

The modulation of cytosolic calcium in the GI system causes a vasoconstrictive effect that is separate from the eicosanoid pathway. The exact pathway of calcium increase is currently unknown, but research has shown that the calcium release occurs in a twophase fashion [36]. The first phase of calcium derives from intracellular stores, while the second-phase derives from extracellular sources (Figure 4). Similar to what occurs in the respiratory system, intracellular release of calcium is an IP3-independent pathway which can be blocked with cAMP inhibitors. The second phase was found to be dependent on IP3-K and the Rho-K pathway [37].

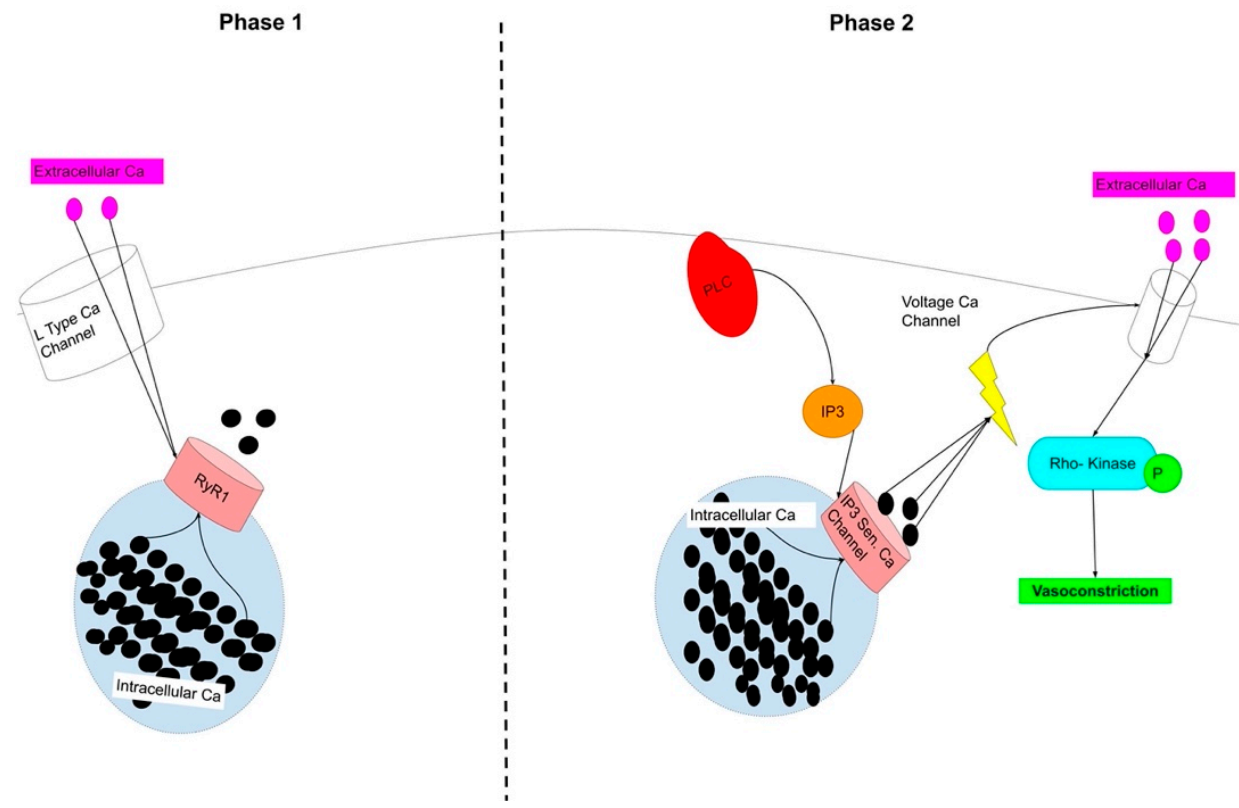

Figure 4. The proposed mechanism for the two-stage, calcium-induced vasocontraction consists of first increased calcium from the sarcoplasmic reticulum via the ryanodine receptor (RyR1). This is followed by an IP3-dependent increase in calcium from intracellular stores which leads to a voltage change and additional rise in intracellular calcium leading to Rho-kinase activation and vasoconstriction.

Additionally, PAF has been linked to increased intestinal edema that was, at first, thought to be correlated with the increase in intracellular calcium and its effect on cadherin adhesion [37]. While this is true, there is an additional effect that extracellular calcium has on intestinal edema. In PAF-induced models, intestinal edema is stabilized after phosphodiesterase (PDE) inhibitor administration, which increases cAMP, as found in sepsis models. However, the increase in cAMP here leads to other side effects such as 
decreased intestinal motility and malabsorption, perhaps indicating a limited potential for the clinical use of PDE inhibitors for intestinal failure patients [37].

While it is well known that PAF can produce a proinflammatory state through increases in neutrophil migration and TNF-a production, its connection to specific inflammatory states has not been widely studied. One such instance is in intestinal reperfusion injury. After ischemic injury, it is well known that an increase in reactive oxygen species and proinflammatory cytokines contributes to reperfusion injury of the tissue. In a knockdown mice model of PAFR, after ischemic occlusion of the superior mesenteric artery, there was a significant decrease in the amount of TNF-a with a concomitant increase in the amount of IL-10 seen in local intestinal and lung tissue samples when compared to wildtype mice [38]. Furthermore a PAFR antagonist was used to show that in the wildtype model, the same decrease in TNF-a and increase in IL-10 was reproducible [39]. While neither of these methods successfully prevented death after ischemia, there was a significant delay in lethality [38].

Another well studied disease state is NEC. While this disease is well known for its origin starting with TLR activation, one of its more detrimental effects is an increase in proinflammatory cytokines [39]. Due to an imbalance of PAF vs. PAF-AH, there is a net increase in PAF leading to increase in inflammation [40]. This concept has been confirmed using a variety of methodologies. Use of a PAF antagonist and supplementation with PAF-AH both showed a decreased rate of NEC infection, while PAF-AH knockout models showed an increase in the rate of NEC [40-42]. This could represent a revolutionary change in the way that NEC is managed, as treatment is currently supportive, there is a potential for PAF modulation during treatment.

PAF has also been implicated in a more vasoactive role in the gastrointestinal system, specifically within the microcirculation [43]. Following a mucosal burn injury, blood flow to the affected areas is normally decreased by up to $65 \%$ resulting in ischemic injury [44]. In normal circumstances, PAF has vasoconstrictive effects; thus, it has been hypothesized that increased PAF within the GI microcirculation would add to ischemic insult following mucosal burns. In the presence of a PAF antagonist, it was seen that there was a significant decrease in the amount of ischemic injury present after mucosal burns [44]. This demonstrates that PAF does have a role in worsening ischemic injury.

\section{Conclusions}

PAF clearly plays a vital role in many organ systems, from the central nervous system to the heart and lungs. Although it has been studied for decades, much is still unknown about its exact function in every organ system. Even within each organ system there appear to be some contradictions, with both protective and harmful effects on the heart, for instance. PAF's role in infections is not straightforward either, as it has protective effects against some bacteria but facilitates infections by others. It is very likely that PAF plays a balancing role in the body, similar to that of cytokines or reactive oxygen species. Discovering more of the downstream pathways of PAF may also produce new avenues of research. PAF's additional role in facilitating infections represents a potential alternative to antibiotics. PAF has the potential to be a new innovative target for treatment in cases of Alzheimer's Disease, NEC, and cystic fibrosis where current treatment is supportive only.

Our review casts light on the complexity of the exact pathways for PAF, and how these contribute to its various functions within specific organ systems (Figure 5). While there are some common effects of PAF within major organ systems, there appears to be some organ specific functionality of PAF as well. We note that PAF is involved in inflammation and vasoconstriction in all the organ systems discussed herein. However, we also found that PAF has some individual functions that are organ specific, such as vascular remodeling, increased edema, and endothelial permeability. 
Platelet Activating Factor Function by Organ System

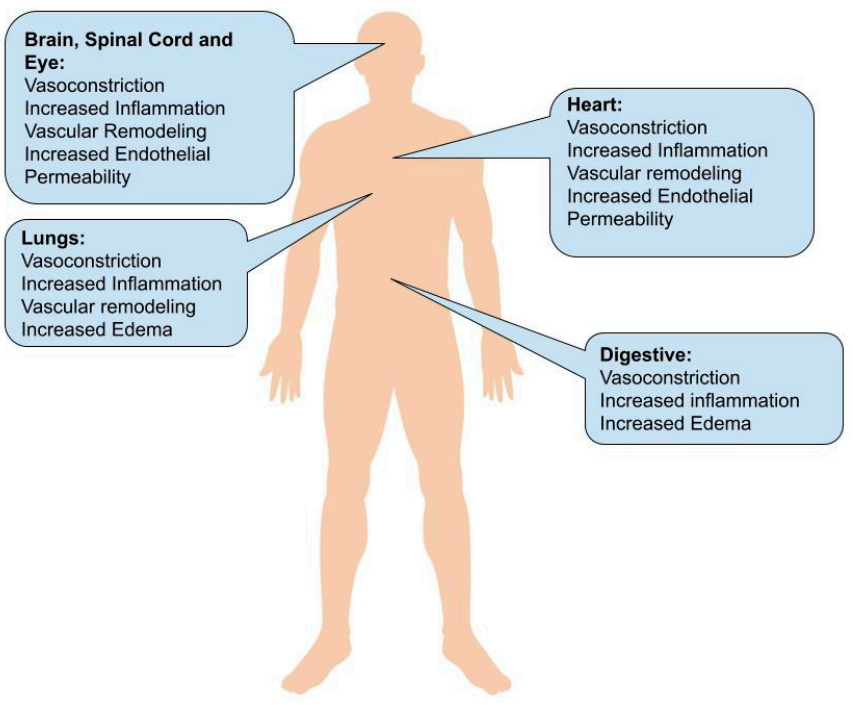

Figure 5. Summary of the function of PAF within each body system.

Based on our review, we believe PAF has several medical implications. One of the most common medical conditions in the United States, atherosclerosis, develops due to cholesterol accumulation in arteries, a process known as atherogenesis. Administering PAFR antagonists or synthetic PAF-AH could slow the progression of atherosclerosis. PAFR antagonist administration could also play a role in the emergency setting, as PAF has been shown to be released from the heart during myocardial infarction leading to left ventricular dysfunction and increased incidence of ventricular arrhythmias. PAFR antagonist administration could reduce these deleterious effects. Due to its role in intestinal reperfusion injury, the development of PAFR antagonists could reduce reperfusion injury of the tissue. PAFR antagonists may also play a role in burn patients with gastrointestinal involvement, as PAFR antagonists could reduce the extent of ischemic injury.

Because of the complexity of each organ system and the irregular pattern in which PAF functions, more research is needed to fully understand the full extent of functionality. At this time, due to the variety of functions of PAF within different organ systems, a common pathway cannot be inferred from literature research alone; however, it highlights promising avenues for future research into using the PAF pathway as a treatment modality.

Author Contributions: All co-authors of this review were active participants to these studies reviewed herein. All authors have read and agreed to the published version of the manuscript.

Funding: This research did not receive any specific grant from funding agencies in the public, commercial, or not-for-profit sectors. This work was not supported financially by any institution.

Institutional Review Board Statement: Not applicable.

Informed Consent Statement: Not applicable.

Data Availability Statement: Data available on request due to restrictions (e.g., privacy, manuscripts under review, or ethical reasons). Most of the data, presented in this study, are available on request from the corresponding author. Data sharing not applicable. No new data were created or analyzed in this study.

Acknowledgments: We are very grateful to Zumit Himank Shah, Laxit Himank Shah, Sasha Taylor, Tate Pumphrey, Radha Sanjay Shah, Ved Bhavin Patel and Kena Piyush Patel for their generous help in editing this manuscript.

Conflicts of Interest: The authors declare no conflict of interest. 


\section{References}

1. Palur Ramakrishnan, A.V.K.; Varghese, T.P.; Vanapalli, S.; Nair, N.K.; Mingate, M.D. Platelet activating factor: A potential biomarker in acute coronary syndrome? Cardiovasc. Ther. 2017, 35, 64-70. [CrossRef]

2. Reznichenko, A.; Korstanje, R. The Role of Platelet-Activating Factor in Mesangial Pathophysiology. Am. J. Pathol. 2015, 185, 888-896. [CrossRef]

3. Gill, P.; Jindal, N.L.; Jagdis, A.; Vadas, P. Platelets in the immune response: Revisiting platelet-activating factor in anaphylaxis. J. Allergy Clin. Immunol. 2015, 135, 1424-1432. [CrossRef]

4. Kelesidis, T.; Papakonstantinou, V.; Detopoulou, P.; Fragopoulou, E.; Chini, M.; Lazanas, M.C.; Antonopoulou, S. The Role of Platelet-Activating Factor in Chronic Inflammation, Immune Activation, and Comorbidities Associated with HIV Infection. AIDS Rev. 2015, 17, 191-201.

5. Papakonstantinou, V.D.; Lagopati, N.; Tsilibary, E.C.; Demopoulos, C.A.; Philippopoulos, A.I. A Review on Platelet Activating Factor Inhibitors: Could a New Class of Potent Metal-Based Anti-Inflammatory Drugs Induce Anticancer Properties? Bioinorg. Chem. Appl. 2017, 2017, 6947034. [CrossRef]

6. Hostettler, M.E.; Knapp, P.E.; Carlson, S.L. Platelet-activating factor induces cell death in cultured astrocytes and oligodendrocytes: Involvement of caspase-3. Glia 2002, 38, 228-239. [CrossRef] [PubMed]

7. Osborne, C.; West, E.; Bate, C. The phospholipase A2 pathway controls a synaptic cholesterol ester cycle and synapse damage. J. Cell Sci. 2018, 131, jcs211789. [CrossRef]

8. Wu, Y.; Wang, L.; Dai, C.; Ma, G.; Zhang, Y.; Zhang, X.; Wu, Z. Neuroprotection by platelet-activating factor acetylhydrolase in a mouse model of transient cerebral ischemia. Neurosci. Lett. 2014, 558, 26-30. [CrossRef] [PubMed]

9. Brailoiu, E.; Barlow, C.L.; Ramirez, S.H.; Abood, M.E.; Brailoiu, G.C. Effects of Platelet-Activating Factor on Brain Microvascular Endothelial Cells. Neuroscience 2018, 377, 105-113. [CrossRef] [PubMed]

10. Wang, Y.; Gao, Z.; Zhang, Y.; Feng, S.-Q.; Liu, Y.; Shields, L.B.E.; Zhao, Y.-Z.; Zhu, Q.; Gozal, D.; Shields, C.B.; et al. Attenuated Reactive Gliosis and Enhanced Functional Recovery Following Spinal Cord Injury in Null Mutant Mice of Platelet-Activating Factor Receptor. Mol. Neurobiol. 2016, 53, 3448-3461. [CrossRef] [PubMed]

11. Codeluppi, S.; Svensson, C.; Hefferan, M.P.; Valencia, F.; Silldorff, M.D.; Oshiro, M.; Marsala, M.; Pasquale, E.B. The Rheb-mTOR Pathway Is Upregulated in Reactive Astrocytes of the Injured Spinal Cord. J. Neurosci. 2009, 29, 1093-1104. [CrossRef]

12. He, J. Alkali-Induced Corneal Stromal Melting Prevention by a Novel Platelet-Activating Factor Receptor Antagonist. Arch Ophthalmol. 2006, 124, 70. [CrossRef]

13. Bazan, H.E.P.; Ottino, P. The role of platelet-activating factor in the corneal response to injury. Prog. Retin Eye Res. 2002, 21, 449-464. [CrossRef]

14. Sharif, N.A.; Xu, S.; Hellberg, P.E.; Pang, I.-H.; Gamache, D.A.; Yanni, J.M. Human conjunctival epithelial cell responses to platelet-activating factor (PAF): Signal transduction and release of proinflammatory cytokines. Mol. Vis. 2009, 15, $1153-1161$. [PubMed]

15. Penna, C.; Alloatti, G.; Cappello, S.; Gattullo, D.; Berta, G.N.; Mognetti, B.; Losano, G.; Pagliaro, P. Platelet-activating factor induces cardioprotection in isolated rat heart akin to ischemic preconditioning: Role of phosphoinositide 3-kinase and protein kinase C activation. Am. J. Physiol. Heart Circ. Physiol. 2005, 288, H2512-H2520. [CrossRef] [PubMed]

16. Penna, C.; Bassino, E.; Alloatti, G. Platelet activating factor: The good and the bad in the ischemic/reperfused heart. Exp. Biol. Med. 2011, 236, 390-401. [CrossRef]

17. Montrucchio, G.; Alloatti, G.; Camussi, G. Role of Platelet-Activating Factor in Cardiovascular Pathophysiology. Physiol. Rev. 2000, 80, 1669-1699. [CrossRef]

18. Zheng, G.-H.; Xiong, S.-Q.; Mei, L.-J.; Chen, H.-Y.; Wang, T.; Chu, J.-F. Elevated Plasma Platelet Activating Factor, Platelet Activating Factor Acetylhydrolase Levels and Risk of Coronary Heart Disease or Blood Stasis Syndrome of Coronary Heart Disease in Chinese: A Case Control Study: A Case-Control Study. Inflammation 2012, 35, 1419-1428. [CrossRef]

19. Quarck, R.; De Geest, B.; Stengel, D.; Mertens, A.; Lox, M.; Theilmeier, G.; Michiels, C.; Raes, M.; Bult, H.; Collen, D.; et al Adenovirus-Mediated Gene Transfer of Human Platelet-Activating Factor-Acetylhydrolase Prevents Injury-Induced Neointima Formation and Reduces Spontaneous Atherosclerosis in Apolipoprotein E-Deficient Mice. Circulation 2001, 103, $2495-2500$. [CrossRef]

20. Lemjabbar, H.; Basbaum, C. Platelet-activating factor receptor and ADAM10 mediate responses to Staphylococcus aureus in epithelial cells. Nat. Med. 2002, 8, 41-46. [CrossRef]

21. Altura, B.; Shah, N.; Shah, G.; Perez-Albela, J.L.; Altura, B. Insights into the possible mechanisms by which platelet-activating factor and PAF-receptors function in vascular smooth muscle in magnesium deficiency and vascular remodeling: Possible links to atherogenesis, hypertension and cardiac failure. Int. J. Cardiol. Res. 2016, 3, 1-3.

22. Uhlig, S.; Göggel, R.; Engel, S. Mechanisms of platelet-activating factor (PAF)-mediated responses in the lung. Pharmacol. Rep. PR 2005, 57, S206-S221.

23. Martin, C.; Göggel, R.; Ressmeyer, A.-R.; Uhlig, S. Pressor responses to platelet-activating factor and thromboxane are mediated by Rho-kinase. Am. J. Physiol. Lung Cell Mol. Physiol. 2004, 287, L250-L257. [CrossRef]

24. Yu, Y.; Zhang, M.; Zhang, X.; Cai, Q.; Zhu, Z.; Jiang, W.; Xu, C. Transactivation of epidermal growth factor receptor through platelet-activating factor/receptor in ovarian cancer cells. J. Exp. Clin. Cancer Res. 2014, 33, 85. [CrossRef] [PubMed] 
25. Burgel, P.-R. Roles of epidermal growth factor receptor activation in epithelial cell repair and mucin production in airway epithelium. Thorax 2004, 59, 992-996. [CrossRef]

26. LeMessurier, K.S.; Häcker, H.; Chi, L.; Tuomanen, E.; Redecke, V. Type I Interferon Protects against Pneumococcal Invasive Disease by Inhibiting Bacterial Transmigration across the Lung. PLoS Pathog. 2013, 9, e1003727. [CrossRef]

27. Shukla, S.D.; Sohal, S.S.; O’Toole, R.F.; Eapen, M.S.; Walters, E.H. Platelet activating factor receptor: Gateway for bacterial chronic airway infection in chronic obstructive pulmonary disease and potential therapeutic target. Expert Rev. Respir. Med. 2015, 9, 473-485. [CrossRef] [PubMed]

28. Tejera Alvarez, P.; Zhang, R.; Su, L.; Christiani, D. Decreased Expression in Platelet-Activating Factor Acetylhydrolase (PAF-AH) Gene Is Associated with ARDS. Am. J. Respir. Crit. Care Med. 2018, 197, A7530.

29. Garcia, C.C.; Russo, R.C.; Guabiraba, R.; Fagundes, C.T.; Polidoro, R.B.; Tavares, L.P.; Salgado, A.P.C.; Cassali, G.D.; Sousa, L.P.; Machado, A.V.; et al. Platelet-Activating Factor Receptor Plays a Role in Lung Injury and Death Caused by Influenza A in Mice. PLoS Pathog. 2010, 6, e1001171. [CrossRef] [PubMed]

30. Lv, X.-X.; Liu, S.-S.; Li, K.; Cui, B.; Liu, C.; Hu, Z.-W. Cigarette smoke promotes COPD by activating platelet-activating factor receptor and inducing neutrophil autophagic death in mice. Oncotarget 2017, 8, 74720-74735. [CrossRef]

31. Sharma, J.; Young, D.M.; Marentette, J.O.; Rastogi, P.; Turk, J.; McHowat, J. Lung endothelial cell platelet-activating factor production and inflammatory cell adherence are increased in response to cigarette smoke component exposure. Am. J. Physiol. Lung Cell Mol. Physiol. 2012, 302, L47-L55. [CrossRef]

32. Shukla, S.D.; Muller, H.K.; Latham, R.; Sohal, S.S.; Walters, E.H. Platelet-activating factor receptor (PAFr) is upregulated in small airways and alveoli of smokers and COPD patients: Small airway PAFr expression in COPD. Respirology 2016, 21, 504-510. [CrossRef]

33. Shukla, S.; Sohal, S.; Mahmood, M.; Reid, D.; Muller, H.; Walters, E. Airway epithelial platelet-activating factor receptor expression is markedly upregulated in chronic obstructive pulmonary disease. Int. J. Chron. Obstruct. Pulmon. Dis. 2014, 9, 853-861. [CrossRef]

34. Riaz, M.S.; Kaur, A.; Shwayat, S.N.; Behboudi, S.; Kishore, U.; Pathan, A.A. Direct Growth Inhibitory Effect of Platelet Activating Factor C-16 and Its Structural Analogs on Mycobacteria. Front. Microbiol. 2018, 9, 1903. [CrossRef]

35. Lautenschläger, I.; Wong, Y.L.; Sarau, J.; Goldmann, T.; Zitta, K.; Albrecht, M.; Frerichs, I.; Weiler, N.; Uhlig, S. Signalling mechanisms in PAF-induced intestinal failure. Sci. Rep. 2017, 7, 13382. [CrossRef] [PubMed]

36. Souza, D.G.; Pinho, V.; Soares, A.C.; Shimizu, T.; Ishii, S.; Teixeira, M.M. Role of PAF receptors during intestinal ischemia and reperfusion injury. A comparative study between PAF receptor-deficient mice and PAF receptor antagonist treatment: PAF receptor and reperfusion injury. Br. J. Pharmacol. 2003, 139, 733-740. [CrossRef] [PubMed]

37. Frost, B.L.; Caplan, M.S. Necrotizing enterocolitis: Pathophysiology, platelet-activating factor, and probiotics. Semin. Pediatr. Surg. 2013, 22, 88-93. [CrossRef] [PubMed]

38. Lu, J.; Pierce, M.; Franklin, A.; Jilling, T.; Stafforini, D.M.; Caplan, M. Dual Roles of Endogenous Platelet-Activating Factor Acetylhydrolase in a Murine Model of Necrotizing Enterocolitis. Pediatr. Res. 2010, 68, 225-230. [CrossRef] [PubMed]

39. Caplan, M.S.; Hedlund, E.; Adler, L.; Lickerman, M.; Hsueh, W. The Platelet-Activating Factor Receptor Antagonist WEB 2170 Prevents Neonatal Necrotizing Enterocolitis in Rats. J. Pediatr. Gastroenterol. Amp. Nutr. 1997, 24, 296-301. [CrossRef]

40. Caplan, M.S.; Lickerman, M.; Adler, L.; Dietsch, G.N.; Yu, A. The Role of Recombinant Platelet-Activating Factor Acetylhydrolase in a Neonatal Rat Model of Necrotizing Enterocolitis. Pediatr. Res. 1997, 42, 779-783. [CrossRef]

41. Yu, P.-W.; Xiao, G.X.; Qin Xj, X.; Zhou, L.-X.; Wang, Z.-Q. The effects of PAF antagonist on intestinal mucosal microcirculation after burn in rats. World J. Gastroenterol. 2000, 6, 906-908. [CrossRef] [PubMed]

42. Cicchitti, L.; Martelli, M.; Cerritelli, F. Chronic Inflammatory Disease and Osteopathy: A Systematic Review. PLoS ONE 2015, 10, e0121327. [CrossRef] [PubMed]

43. Perez, L.L.; Sneed, J.A.; Eland, D. Evidence-based osteopathic manipulative treatment for common conditions. Osteopath Fam. Physician 2012, 4, 8-12. [CrossRef]

44. Hibler, J.; Perkins, J.; Eland, D.; Sammons, D. Osteopathic Manipulative Medicine for Inflammatory Skin Diseases. Available online: https://cdn.ymaws.com/www.aocd.org/resource/resmgr/jaocd/contents/volume31/31-01.pdf (accessed on 1 November 2021). 